\title{
CROMOTERAPIA, AMBIÊNCIA E ACOLHIMENTO AO USUÁRIO DO SUS NAS ESFS
}

José Merenda Junior', Maria Cecília Doria de Toledo Sylla

${ }^{1}$ Aluno do curso de Medicina da Universidade do Oeste Paulista - UNOESTE. E-mail: josemerendajunior@hotmail.com

\section{RESUMO}

O presente trabalho aborda a Cromoterapia no contexto da Política Nacional de Humanização (PNH) colocando as cores como ferramentas para melhorar o bem estar do usuário do Sistema Único de Saúde (SUS) em consonância com a ideia de ambiência e tendências de humanização na Saúde Pública Brasileira. Este trabalho surgiu com a idéia de melhorar o acolhimento dos usuários do SUS nas Estratégias de Saúde da Família (ESF), aplicando o conceito de ambiência de um modo econômico, prático e de fácil aplicação. A cor apresenta uma influência direta ou indireta no nosso cotidiano, quando utilizada de maneira adequada, pode apresentar-se de forma extremamente importante como ferramenta para o equilíbrio de ambientes e seres, podendo gerar bem estar, preservando a saúde.

Palavras-Chave: Cromoterapia, Sistema Único de Saúde, Humanização da Assistência, Saúde da família, Acolhimento.

\section{INTRODUÇÃO}

Nos últimos anos o Sistema Único de Saúde (SUS) tem sido um dos temas mais discutidos no âmbito da saúde nacional devido a sua necessidade de adequar seus serviços, tornando-o mais seguro, acessível e acolhedor (PINHO, 2005).

Através do programa Humaniza SUS o Ministério da Saúde vêm difundindo o conceito de ambiência como nova ferramenta. Ambiência, especificamente na saúde, segundo o Ministério da Saúde (2001), significa: “o tratamento dado ao espaço físico entendido como espaço social, profissional e de relações interpessoais que deve proporcionar atenção acolhedora, resolutiva e humana." Com isso atingiu-se um avanço qualitativo no conceito de humanização de territórios da saúde pública, visando o conforto e o melhor acolhimento do usuário.

A cromoterapia pode ser utilizada como ferramenta da ambiência pode auxiliar na formação de um ambiente mais acolhedor proporcionando conforto e segurança aos usuários do SUS.

O presente artigo explora o conceito de ambiência no espaço de saúde específico dos postos de ESFs, através do uso programado de cores para melhor acolher os usuários como preconiza o Programa Nacional de Humanização - PNH. 


\section{MÉTODO}

Este trabalho é uma pesquisa de revisão integrativa e tem como objetivo revisar a literatura e definir conceitos gerais, possibilitando assim, um entendimento para os planejadores da área da saúde a fim de proporcionar novas ferramentas de acolhimento dos usuários.

Foi realizada uma busca no Google acadêmico no período de Janeiro de 2012 a Julho de 2013, além de consulta a livros específicos de cromoterapia e sites do Ministério da Saúde. Os critérios de inclusão das referências foram comentar a política Nacional de Humanização (PNH) e o conceito de ambiência, e também textos científicos sobre o estudo das cores e suas aplicações voltadas para a área da saúde.

O estudo vigente analisou o conteúdo de três (3) sites: Ministério da Saúde, Associação Brasileira de Medicina Complementar (ABMC), e um terceiro sobre humanização. Também foram analisados sete (5) livros sobre cromoterapia e uma (1) monografia de graduação de curso. A análise crítica dos dados foi desempenhada por meio de leitura com uma visão crítica do conteúdo analisado, seguindo de reflexão do tema.

\section{RESULTADOS}

O estudo das fontes mencionadas abaixo permitiu analisar vários autores possibilitando a discussão dos temas citados nesse trabalho. Após análise crítica do material selecionado, o resultado foi o seguinte:

O acolhimento na saúde, além do sentido trivial referente ao processo de abordagem do usuário, também engloba o espaço físico no qual este é recebido. Esse espaço deve estar preparado adequadamente para proporcionar o conforto, bem estar e a privacidade do mesmo. Deve-se projetar ambientes acolhedores e harmônicos distanciando a ideia de frieza e hostilidade que acompanham os ambientes de saúde no Brasil. 
Tabela1. distribuição dos textos lidos de acordo com o ano de publicação, título, autores e temática.

\begin{tabular}{|c|c|c|c|}
\hline $\begin{array}{c}\text { Ano de } \\
\text { publicação }\end{array}$ & Título & Autores & Temática \\
\hline 1988 & Doutrina das cores & Goethe, J.W. & Cromoterapia \\
\hline 1995 & $\begin{array}{l}\text { A energia criativa através das } \\
\text { cores }\end{array}$ & Gimbel, T. & Cromoterapia \\
\hline 2002 & $\begin{array}{l}\text { Ergonomia e Alzheimer: } \\
\text { contribuição dos fatores } \\
\text { ambientais como recuso } \\
\text { terapêutico }\end{array}$ & Pascale, M.A. & Ambiência \\
\hline 2003 & $\begin{array}{l}\text { O computador no ensino- } \\
\text { aprendizagem de criação de } \\
\text { desenhos têxteis }\end{array}$ & Schulte, N.K. & Uso das cores \\
\hline 2005 & $\begin{array}{c}\text { A humanização do ambiente } \\
\text { hospitalar sob o olhar da } \\
\text { cromotécnica }\end{array}$ & Pinho, T.P.A. & $\begin{array}{l}\text { Humanização, } \\
\text { ambiência e } \\
\text { cromoterapia }\end{array}$ \\
\hline 2006 & A psicologia das cores & Heller, E. & $\begin{array}{l}\text { Cromoterapia e } \\
\text { psicologia }\end{array}$ \\
\hline 2006 & $\begin{array}{l}\text { Cromoterapia: qualidade das } \\
\text { cores e técnicas de aplicação }\end{array}$ & Sophy, M. & Cromoterapia \\
\hline 2012 & $\begin{array}{c}\text { Antonio Candido, } 80 \text { anos de } \\
\text { humanização }\end{array}$ & Fester,ACR. & Humanização do SUS \\
\hline
\end{tabular}

Adotando o conceito de ambiência para a arquitetura nos espaços de saúde, gera-se uma melhor qualidade no acolhimento do usuário. É importante que, ao criar essas ambiências, leve-se em consideração os valores culturais da comunidade em que a ESF esta inserida.

A cromoterapia pode ser utilizada como ferramenta estratégica para formação de um ambiente mais acolhedor, proporcionando conforto e segurança aos usuários do SUS. As cores exercem grande influência no ambiente modificando-o, animando-o e assim podendo alterar a comunicação, atitudes e percepção das pessoas presentes, pois todos temos reações frente às cores. 
Tabela2. distribuição de sites lidos de acordo com data de acesso, nome, link e consideração temática.

\begin{tabular}{|c|c|c|c|}
\hline $\begin{array}{l}\text { Data de } \\
\text { Acesso }\end{array}$ & Nome & Link & $\begin{array}{l}\text { Consideração } \\
\text { /Temática }\end{array}$ \\
\hline $10 / 06 / 2012$ & $A B M C$ & $\frac{\text { www.medicinacomplementar.com.br/ }}{\text { estrategia cromoterapia.asp\#2 }}$ & Cromoterapia \\
\hline 02/07/2012 & $\begin{array}{l}\text { Ministério da } \\
\text { Saúde - Portal } \\
\text { Saúde }\end{array}$ & $\frac{\text { http://bvsms.saude.gov.br/bvs/publicacoes/c }}{\text { adernos humanizaSUS.pdf }}$ & $\begin{array}{l}\text { Humanização e } \\
\text { SUS }\end{array}$ \\
\hline 05/07/2012 & $\begin{array}{l}\text { Ministério da } \\
\text { Saúde - Portal } \\
\text { Saúde }\end{array}$ & $\frac{\text { http://bvsms.saude.gov.br/bvs/publicacoes/p }}{\underline{\text { nhah01.pdf }}}$ & $\begin{array}{c}\text { Humanização } \\
\text { da Assistência } \\
\text { Hospitalar }\end{array}$ \\
\hline $20 / 06 / 2013$ & $\begin{array}{l}\text { Ministério da } \\
\text { Saúde - Portal } \\
\text { Saúde }\end{array}$ & $\frac{\text { http://bvsms.saude.gov.br/bvs/dicas/170 am }}{\underline{\text { biencia.htm }}}$ & Ambiência \\
\hline
\end{tabular}

\section{DISCUSSÃO}

O termo humanização é definido como o processo que proporciona no homem o exercício da reflexão e da percepção para com o próximo gerando o afinamento das emoções e a capacidade de penetrar nos problemas da vida cultivando a empatia (FESTER, 2005).

A humanização passou a ser ferramenta do SUS na criação de programas municipais de humanização do parto, programa este que era fortemente apoiado por organizações não governamentais e da população em geral, podendo ser considerado pioneiro na humanização dos serviços de saúde no Brasil (PINHO, 2005).

O segundo grande momento da humanização da saúde pública foi a implantação do Programa Nacional de Humanização da Assistência Hospitalar (PNHAH) implantado no ano de 2000, criado pelo Ministério da Saúde marcando a inserção do Estado na procura de um programa que gerasse atendimento igualitário para todos (PINHO, 2005).

O terceiro e atual momento se iniciou com a implantação da Política Nacional de Humanização (PNH) criado no ano de 2003, ainda em fase de implantação, vem buscando modificações estruturais e organizacionais nos atendimentos hospitalares do SUS (PINHO, 2005). Ainda para fortalecer a PNH foi criada a proposta de uma Política Estadual de Humanização (PEH) que permite um esforço conjunto na criação / implantação de novos métodos de atendimento aos usuários e técnicas de gestão dos serviços (BRASIL, 2001). 
Entende-se assim que a responsabilidade é do Estado em conjunto com os municípios em implementar políticas que viabilizem os princípios e as diretrizes prioritárias do SUS. A Política Estadual de Humanização tem como principal tarefa adequar a proposta nacional à realidade da comunidade local. Segundo Pinho (2005) a humanização na saúde trata-se então, uma reformulação da relação médico paciente fortalecendo a ideia dos diretos do paciente enquanto ser humano.

A PNH tem como uma ferramenta o conceito de ambiência, adotado pela necessidade de criar ambientes que contribuíssem na mudança das relações de trabalho. Segundo a própria PNH a ambiência se resume em três situações principais (BRASIL, 2009):

1. Espaço que visa conforto;

2. Espaço como ferramenta facilitadora do processo de trabalho;

3. Espaço para encontros entre os sujeitos.

As cores exercem influência sobre as ações, emoções e sentimentos cotidianamente em todos nós seres humanos. Se observarmos ao nosso redor, a natureza tem cor, fauna, flora e a luz solar são naturalmente coloridas, e estas podem ser percebidas ao decorrer da evolução do mundo.

A escolha das cores é fundamental para harmonia dos elementos, ela afeta as atividades musculares, mental e nervosa. A combinação das cores afeta o psicológico, podendo causar efeitos como de excitação, calma, melancolia, segurança, etc (HELLER, 2009).

Cromoterapia ou Colorterapia é definida por Sophy (2003) como sendo uma ciência a qual usa as cores na busca do equilíbrio do ser humano, pois com a aplicação das cores pode-se alterar ou manter a vibração que nos proporcionam saúde.

As cores estão presentes na vida de todos os seres desde o inicio, fazendo parte da nossa existência. O olho necessita dela tanto quanto da luz, pois proporciona grande prazer (GOETHE, 1988). Schulte (2003) considera que a cor "tem um valor informativo através dos significados que se the adicionam simbolicamente. A cor pode ser explorada para diversas finalidades funcionais, psicológicas, mercadológicas, cromoterápicas e outras".

A cor também pode ser usada como um instrumento no processo de cura, de acordo com estudos de Pascale (2002) "ha uma evidência crescente em relação à influência das cores no sono, no estado de alerta, nas emoções e na saúde, interferindo fortemente no dia a dia. Usando corretamente as cores pode-se melhorar a qualidade de vida de um individuo" 
De acordo com a Associação Brasileira de Medicina Complementar (ABMC) a cromoterapia conquista cada vez mais espaço na sociedade graças aos avanços tecnológicos que permitem avanços científicos na área e aumentando sua credibilidade (ABMC, 2012). Vale ressaltar que a prática da cromoterapia não dispensa o tratamento médico convencional, recomenda-se ser utilizada paralelamente, como terapia complementar.

No estudo sobre cromoterapia de Gimbel (1995), fez-se os seguintes apontamentos: o verde como cor estimulante do crescimento, sendo clara é relaxante sem ser depressiva; azul sendo a mais curativa, relaxa o corpo todo e regula o desenvolvimento harmonioso do tecido e da estrutura orgânica; turquesa como cor reanimadora, refrescante, que tranquiliza o sistema nervoso; amarelo que proporciona a sensação de afastamento e estimula o sistema nervoso; laranja é a cor da alegria, antidepressiva e benéfica no sistema metabólico; violeta compõe-se do relaxante azul e do estimulante vermelho sendo a cor do equilíbrio, da consciência e da estabilidade; o branco representa a pureza na sua forma extrema, como o preto, não constitui uma cor suportada por muito tempo pela maioria das pessoas; e finalmente o preto, sendo uma cor temida, suspeitosa, ligada à morte e ao perigo.

\section{CONCLUSÃO}

O processo de humanização vem sendo amplamente aplicado no âmbito hospitalar através de ações que contemplam desde o espaço físico, estendendo-se para todo o cuidar. Entretanto pouca atenção é dada à humanização no ambiente de atenção básica, principalmente voltada ao espaço físico.

Os espaços da atenção básica onde ocorrem os encontros entre os profissionais de saúde e a população não favorecem uma experiência agradável, carecendo de ações que podem tornar esse ambiente mais prazeroso para os usuários. As cores podem ser uma ferramenta útil já que estimulam nossos sentidos e, quando usadas corretamente, podem melhorar a experiência.

A partir do estudo das cores entendemos que o usuário do SUS pode se beneficiar com a utilização da cromoterapia para melhorar seu estado biopsicossocial. Esperamos que este estudo sirva de referência e/ou instrumento de trabalho para gestores da saúde nos diferentes âmbitos e unidades do SUS e para usuários que participam da gestão participativa da Política de Saúde brasileira. 


\section{REFERÊNCIAS}

Associação Brasileira de Medicina Complementar. Cromoterapia [Internet]. [acesso em 2012 jun 10]. Disponível em: www.medicinacomplementar.com.br/estrategia_cromoterapia.asp\#2

Fester ACR. Antonio Candido, 80 anos de humanização [Internet]. [acesso em 2012 jun 10]. Disponível em: http://www.dhnet.org.br/direitos/militantes/fester/candid80.htm

Gimbel T. A energia criativa através das cores. São Paulo: Pensamento; 1995;(1)p.17-42

Goethe JW. Doutrina das cores. São Paulo: Nova Alexandria; 1988;14(4) p.7-272

Heller E. A Psicologia das cores. Barcelona: Gustavo Gili SL; 2009;(1)p.50-127

Ministério da Saúde (Brasil). Ambiência [Internet]. Brasília: Ministério da Saúde; 2009 [acesso em 2013 jun 20]. Disponível em: http://bvsms.saude.gov.br/bvs/dicas/170 ambiencia.html

Ministério da Saúde (Brasil). Humaniza SUS [Internet]. Brasília: Ministério da Saúde; 2004. [acesso em 2012 jul 02]. Disponível em:

http://bvsms.saude.gov.br/bvs/publicacoes/cadernos humanizaSUS.pdf

Ministério da Saúde (Brasil). Manual PNHAH [Internet]. Brasília: Ministério da Saúde; 2001. [acesso em 2012 jul 05]. Disponível em: http://bvsms.saude.gov.br/bvs/publicacoes/pnhah01.pdf

Pascale MA. Ergonomia e Alzheimer: a contribuição dos fatores ambientais como recurso terapêutico nos cuidados de idoso portadores da demência tipo Alzheimer [dissertação]. Florianópolis: UFSC; 2002. p.88

Pinho TPA. A humanização do ambiente hospitalar sob o olhar da cromotécnica [monografia]. Rio de Janeiro: Escola Politécnica de Saúde Joaquim Venancio da Fundação Oswaldo Cruz; 2005.

Schulte NK. O computador no ensino-aprendizagem de criação de desenhos têxteis: efeitos na qualidade artística, no emprego da cor e na aplicação têxtil [dissertação]. Florianópolis: UFSC; 2003. p.47

Sophy, M. Cromoterapia: qualidade das cores e técnicas de aplicação. São Paulo: Roca; 2006. (1) 